Dear Author,

Please, note that changes made to the HTML content will be added to the article before publication, but are not reflected in this PDF.

Note also that this file should not be used for submitting corrections. 


\title{
Egocentric contact networks in comparison: Taiwan and Hungary
}

\author{
2 Q1 Beata Dávid ${ }^{\mathrm{a}, \mathrm{b}}$, Eva Huszti ${ }^{\mathrm{c}}$, Ildikó Barna ${ }^{\mathrm{d}}$, Yang-chih Fu ${ }^{\mathrm{e}, *}$ \\ a Institute of Mental Health, Faculty of Health and Public Services, Semmelweis University, Pf. 91, H-1450 Budapest, Hungary \\ Q2 b Hungarian Academy of Sciences Centre for Social Sciences, Hungary \\ c Faculty of Health, University of Debrecen, Sóstói u. 2-4, H-4400 Nyíregyháza, Hungary \\ d Faculty of Social Sciences, Eötvös Loránd University, Pázmány Péter sétány 1/a, H-1117 Budapest, Hungary \\ e Institute of Sociology, Academia Sinica, 128 Academia Rd., Sec. 2, Taipei 115, Taiwan
}

\section{A R T I C L E I N F O}

\section{Keywords:}

Egocentric networks

Contact diary

Cross-cultural studies

Tie strength

\begin{abstract}
A B S T R A C T
This study compares the size and structure of egocentric networks in Taiwan and Hungary using a diary approach. Both countries have transformed from authoritarian regimes to democratic states, yet they differ in social, economic, and cultural institutions that may be common to the respective larger region where each is located. To sample the structure of each egocentric network, we extracted information from largely identical contact diaries collected in both countries, 51 from Taiwan and 138 from Hungary. After comparing sample characteristics, network size, and composition, we construct a Strength of Ties (SoT) index based on two objective and two subjective measures of ego-alter ties. We then use this index to analyze tie strength by the types of relationships. On average, the number of alters contacted in one week is much larger in Taiwan than in Hungary, and the gap remains unchanged after controlling for key socio-demographic background factors. Even though the four indicators that we use to construct the SoT index are distributed similarly among the respondents in both Taiwan and Hungary, the composite index pinpoints how the types of relationships play somewhat different roles across the nations. The findings imply that the tendency to maintain only the closest ties with kin and other close friends is linked to distrust to others, a possible ill effect lingering from the authoritarian past. The implication is partially supported by further analyses using the ISSP 2006 survey data. We address how our findings may contribute to the existing literature on the linkage between societal characteristics and interpersonal ties.
\end{abstract} (c) 2015 Published by Elsevier B.V.

\section{Introduction}

Egocentric networks often vary in size and structure depending on individuals' demographic characteristics, life stages, and other background factors. Larger social forces also can influence how people interact and become connected with others. While the literature has examined such individual variations extensively, social network studies also pay attention to whether and how institutional or other macro-level forces condition egocentric networks. The mechanisms of how individual and institutional factors function may further differ from society to society, making it a difficult task to compare egocentric networks across societies or cultures. In spite of the challenges that cross-societal comparisons pose to social network studies, however, they also hold much potential for

\footnotetext{
* Corresponding author. Tel.: +886 22821 5782/922 632 220; fax: +88622652 5050 .

E-mail addresses: david.bea@public.semmelweis-univ.hu (B. Dávid), husztieva@foh.unideb.hu (E. Huszti),barnaildiko@tatk.elte.hu (I. Barna), fuyc@sinica.edu.tw (Y.-c. Fu).
}

helping advance understanding about how egocentric networks function under the influences of macro-level forces.

In the early stage of comparative network studies, cross-national surveys yielded limited yet helpful information about the frequencies of contacts among strong ties. The 1986 module of the International Social Survey Programme (ISSP, see www.issp.org), for example, helped reveal highly similar structures and patterns of social interactions among its eight member countries (all Western). Several important disparities emerged, however, when comparing these findings to those based on an extra survey from China. First of all, Chinese familial roles tended to be more specialized than their Western counterparts. Spouse, child, and parent each played a distinctive role; as a broader role set they could be separated from other roles more easily, too (Freeman and Ruan, 1997; Ruan et al., 1997). Moreover, families and relatives in China were more likely to give financial support to one another, a phenomenon unusual within Western societies. Similar and more subtle differences have also been reported in subsequent research based on other instruments with "broader replication ... especially in societies without European origin" (Freeman and Ruan, 1997). In particular, comparative studies using the position generator, either conducted 
separately in different national surveys or as identical question items in compatible surveys across societies, have flourished and have become an emerging research paradigm in recent years (Lin and Erickson, 2008; Hsung et al., 2009; Lin et al., 2014).

Following these previous cross-national studies of egocentric networks, this paper uses an alternative "diary" approach to explore whether and how two far-away and seemingly far-apart countries, Taiwan and Hungary, are similar and different in their respective egocentric contact networks. In addition to relying on identical and systematic network data collection, our study contributes to the literature in two ways. First, by comparing one society each from East Asia and Eastern Europe, we examine network compositions that may be linked to larger institutional constraints or the macrolevel forces applicable to each of the regions as a whole. In this case at least two major macro-level forces, kinship systems and democratic transitions, may be at work in shaping contact patterns in everyday life. Second, using largely identical "contact diaries" from both countries, we reconstruct contact networks that can reveal more information about the active subsets of egocentric networks.

For our empirical inquiries we extracted information from weeklong contact diaries, 51 from Taiwan and 138 from Hungary. After comparing sample characteristics, network size, and composition, we constructed a Strength of Ties (SoT) index based on two objective and two subjective measures of ego-alter ties. We then used this index to analyze tie strength by the types of relationships, paying special attention to relationships between kin and non-kin ties in order to confirm and elaborate the major differences suggested by previous comparative studies using other network generators in probability surveys. Using such an alternative diary approach of network studies with a comparative perspective, our study helps shed light on egocentric networks, not only by linking macro-level forces to everyday contact patterns, but also by exploring methodological tools relatively unseen in the literature.

\section{Comparing contact networks across nations: from societal forces to daily interactions}

A brief review over two societal background factors, kinship systems and the recent decades of political-economic developments, in both Taiwan and Hungary raises interesting questions pertinent to the comparative study of contact networks in everyday life. Moreover, such comparisons may also benefit from the relatively rich network literature that both countries have established in their respective regions, East Asia and Eastern Europe. Based on findings from preexisting network studies in both countries, we can further conduct theoretical inquiries using the alternative diary approach that supplements other, more established, network generators.

While being geographically and culturally distinctive from each other, Taiwan and Hungary differ particularly in how extended kin members play their roles in egocentric networks. As heavily influenced by the complicated Chinese kinship system, nearly each of the Taiwanese kin relations is characterized by a unique term. In addition to immediate family, all other relatives comprise an extended kinship network that remains a crucial part of one's life events as well as daily networking (Wolf and Huang, 1985; Yang, 1994; Freeman and Ruan, 1997).

The significance of the extended family in Chinese societies has been also an emerging topic in business studies. Not only is living with the extended family a common practice of family care, but recruiting such kin members as business partners also becomes a preferred model (Yang, 1998; Chua et al., 2009). The concept behind such a cultural practice, "familial collectivism", may be in turn part of "in-group collectivism", one of the nine cultural dimensions encompassing both societal values and actual practices (House et al., 2004). According to such a broad classification of the world's cultures, Taiwan is part of Confucian Asian culture that heavily values putting individuals' pride, loyalty and cohesiveness toward their families (Gelfand et al., 2004). The widespread reliance on guanxi in China and Taiwan (Yang, 1998; Bian and Ang, 1997; Bian and Ikeda, 2014; Chua et al., 2009) further extends panfamilism to various political, economic, and social realms. Among such pan-familism practices, the role of extended family remains salient in personal networks.

In contrast, even though the cultural practices of the Eastern European cluster, to which Hungary belongs, also lean to group and family collectivism (Bakacsi et al., 2002), the Hungarian people hardly extend their trust beyond their close family ties. As shown in a follow-up study of personal network, extended family does not play a significant role in the Hungarians' personal networks, nor is it emotionally important (Kopasz et al., 2008). Under such distinctive East Asian and Eastern European cultural backgrounds, it would be revealing to compare how family members in general, and the relatives beyond one's immediate family in particular, play their roles in egocentric networks in both countries.

In political domain, both Taiwan and Hungary transformed from authoritarian regimes to democratic states in the late 20th century. In 1949, the Republic of China fled from the Chinese Communists and retreated to Taiwan, which was about the same time Hungary became part of the former Soviet bloc. Both single-party regimes exerted extensive and strict political control over their citizens, which they enforced by severe punishments as stipulated in martial laws. Based on either anti-Communist (Taiwan) or Communist (Hungary) ideology, such macro-level structural constraints set up by both authoritarian regimes often led to limited social interactions and personal networks. In particular, the practice of strict surveillance by secret police or police informers was so common that residents refrained from talking to strangers or weakly tied others, especially in public places. Under such circumstances, weak ties often became a liability, full of risks that might easily lead to imprisonment, rather than an asset that might lead to landing a new job (Volker and Flap, 2001; cf. Granovetter, 1973, 1983).

In the late 1980s, however, both countries started transitioning to Western-style democracy. Taiwan lifted its martial law in 1987 and has since seen power transform between major political parties. During the year (2004) when we collected the contact diaries for this study, there had been over 100 legally registered political parties in Taiwan, which increased to 277 as of September, 2015 (MOI, 2014). Hungary also experienced a smooth transition to democracy after the communism fell in 1989. Since then, party politics has been the most active among the former Soviet bloc nations, as evidenced by 84 political parties being officially registered before the 2014 parliamentary election (Spirova, 2008; NEOH, 2014). According to various indicators, furthermore, both Taiwan and Hungary are rated very highly, if not among the highest rated, in terms of both political rights and civil liberties in relation to other countries throughout the world (Freedom House, 2014). Under much improved political circumstances, how do residents in both countries interact and become connected in everyday life?

As studies in China and Taiwan suggest, kin ties seem to prevail in multiple guanxi networks in Chinese or East Asian societies regardless of political or economic systems (Bian and Ang 1997; Ruan et al., 1997; Lin et al., 2014; Bian and Ikeda, 2014). Because Taiwan and Hungary shared the same authoritarian past before moving to emerging democracies, comparing their egocentric networks would be beneficial for testing any possible lingering effects from such macro-level forces. Due to widespread evidence highlighting the significance of extended family ties in Chinese societies, it also would be important to examine whether residents in Taiwan exhibit such strong ties with relatives beyond one's immediate family. 
To examine whether and how such macro-level mechanisms vary between the two countries, this study aims to compare the size and structures of egocentric networks using a diary approach. Because network boundaries tend to be obscure, egocentric networks are difficult to observe, measure, and estimate. The task of sampling and constructing network structures becomes even more challenging when comparing networks across societies, which often differ in various institutional bases of social interactions (Kadusin, 2012; Lin and Erickson, 2008; Lin et al., 2014).

In an effort to understand important network features, researchers have used various generators to obtain a subset of actors and ties that facilitate various analyses. The most widely used generators include the name generator (Laumann, 1973; Wellman, 1979; Fischer, 1982a, 1982b; Burt, 1984; Marsden, 2003) and the position generator (Lin and Dumin, 1986; Erickson, 1996, 2004; Lin et al., 2001). Other proxies or generators, such as the resource generator (Van der Gaag and Snijders, 2004, 2005), small world methods (Milgram, 1967), and reverse small world (RSW) methods (Killworth and Bernard, 1978), also allow researchers to map egocentric networks, as well as examine ego-alter ties (Bernard et al., 1990; Killworth et al., 2006). In general, most name generators help capture strong ties well, while the position generator and the RSW methods tend to cover weaker ties, thus allowing more precise estimation of the network size (Zheng et al., 2006; McCormick et al., 2010).

Although these innovative designs differ in both theoretical and methodological advantages, most generators help collect important information about a focal person (hereafter "ego"), that ego's family, friends, and other acquaintances (hereafter "alters"), and how these alters are tied to ego. The designs also help explore the resources and social supports embedded in ego's network (Huszti et al., 2013; Chua et al., 2011). How well these resources and supports work, in turn, largely depends on the strength of ego-alter ties, as well as other network features.

As important as the strength of ties is to understanding the structure and functions of egocentric networks, however, network generators are subject to recall biases, and some of the questions asked may favor stronger or weaker ego-alter ties. Such biases can be particularly obvious in one-shot surveys and experiments, when people cannot spend more time and effort to recall strong and weak ties, or when the questions are skewed toward specific social situations. As a result, measures of tie strength constructed from network generators tend to omit certain types of ego-alter ties. Instead of relying on a single generator for determining the size and composition of networks, therefore, researchers should explore alternatives and preferably use multiple techniques to reconstruct network structures (Campbell and Lee, 1991; Brewer, 2000; Molin et al., 2008).

Among the alternative instruments that aim to measure more subsets of egocentric networks, contact diaries allow researchers to reconstruct the components of networks that are active in everyday life (Fu, 2005, 2007; Huszti et al., 2013). Unlike other instruments, a contact diary seeks a "weighted random sample" of an egocentric network (Molin et al., 2008:14). Although it is more tedious and demanding to keep a contact diary, it often yields information about various ties that other network generators are less likely to cover (Chua et al., 2011).

By sampling a given period of time, which can range from one day to several months, contact diaries require respondents to track and record all their interpersonal contacts. The longer the diary keeping, the more ego-alter ties will emerge and the better coverage one will obtain to construct indicators of the strength of ego-alter ties. Partly because it is difficult and expensive to collect reliable and valid contact diaries, however, there have been relatively few diary studies in the social-network literature (e.g., Gurevitch, 1961; de Sola Pool and Kochen, 1978; Freeman and Thompson, 1989; see reviews in $\mathrm{Fu}, 2007)$. To achieve relatively compatible data sets from the two countries, we purposely designed the Hungarian contact diary research to follow the format of Taiwan's diary studies, including identical question items and similar answering categories (Fu, 2007). This tedious yet more thorough approach to data collection allowed us to compare more active components of the egocentric networks of an East Asian country to that of an Eastern European country.

\section{Tie strength in egocentric networks}

Network researchers are constantly searching for valid and effective indicators to measure the strength of ties. Empirical attempts at constructing or evaluating such indicators, however, are limited. In many studies, tie strength in egocentric network structures seems a feature taken for granted, without proper or adequate explanations about how to measure tie strength precisely. Some researchers rely on their tacit knowledge rather than make an effort to actually measure these ties (Walker et al., 1993; Mathews et al., 1998; Petróczi et al., 2007).

For practical considerations, researchers tend to accept and adopt the strong-weak dichotomy of tie strength in empirical studies, even though they are aware of a conceptual continuum that connects the two ends. With precise definitions of operation, it is easy to clearly distinguish strong from weak ties. But in theory, it is widely recognized that contacts and relations can be more complicated than being automatically classified as one type or the other (Böröcz and Southworth, 1995). Moreover, using only a strong-weak dichotomy can hide important cross-cultural differences.

Indicators of tie strength can cover a wide range of objective and subjective measures. For example, a recent review identified the following items as possible indicators: (a) frequency of interaction, (b) intimacy or closeness, (c) voluntary investment in the tie, (d) advice given or received, (e) desire for companionship, (f) multiple social context (breadth of topics), (g) duration of contact, (h) reciprocity, (i) support provided or emotional intensity, (j) trust, and (k) sociability or conviviality (Petróczi et al., 2007:41). In addition, styles, timing and location of dyadic contacts, and different cultural values, norms, and expectations are also critical dimensions of making differences between ties (Hite, 2005).

As demonstrated in pioneering studies (Wellman, 1979; Fischer, 1982a), tie strength has been often measured by multiple survey items that range from large to small services people seek when they are in need. Compared to a single, dichotomous distinction between strong and weak ties, such a multidimensional approach better reflects the nature of dyadic ties, which in turn uncovers the main characteristics of egocentric network structures (Hite, 2008). In other seminal works about the conceptualization of key network features, such as Granovetter $(1973,1983)$ "strength of weak ties" and Granovetter (1985) and Uzzi (1996) research on embeddedness, this "multi-dimensional nature of the dyadic context" was also critical (Hite, 2005:146). When both the content and structure of networks are involved in empirical inquiries, it is typically insufficient to use dichotomous labels to indicate the strength of ties or the extent of embeddedness (Petróczi et al., 2007).

Although there is a clear conception of the characteristics of strong ties, it is ambiguous on the theoretical ground whether and how tie strength can be associated with the types of relationships. Researchers usually set out from the assumption that all strong ties are homogeneous and that there are no differences between them. Among the same ties that are embedded with relationships (e.g. relatives), however, actors do not necessarily interact with each other frequently, nor do they always show affection toward each other (Hite, 2003). 
Similar to kinship, a typical relationship designated with "strong ties", the strength of ties has been also closely linked to neighborhood, affiliation, similar socio-economic status, workplace, and occupational prestige, all "grouping variables" commonly used in empirical studies (Haythornthwaite, 2002; Petróczi et al., 2007). Rather than using role relationships as an indicator of tie strength, it should be more revealing and desirable to measure tie strength directly and construct the tie strength index based on empirical data (cf. Marsden and Campbell, 1984, 2012).

Empirical attempts to construct indicators for the strength of ego-alter ties have been based largely on various network generators. By means of network generators, researchers are able to design and ask specific questions according to their research problems of interest. A single questionnaire survey, for example, can cover the above-mentioned dimension of tie strength as widely as possible. By asking respondents to recall their social interactions in one-shot surveys or experiments, researchers need to pay more attention to question probing and interviewer training to alleviate possible recall biases.

In comparison, contact diaries help produce records of social interactions that are active, thus allowing collection of network data that may better capture interpersonal contacts in daily life. As the case with other network generators, however, the diary data are also subject to compliance and honesty from respondents. To minimize any possible biases, researchers need to ensure that the diary keeping follows strict protocols of data collection. Unlike surveys or experiments, diary studies require a longer commitment from study participants. Most contact diaries last from at least one week to 100 days (Gurevitch, 1961; de Sola Pool and Kochen, 1978; Freeman and Thompson, 1989; Lonkila, 1999; Fu, 2005, 2007), except for the 24-h or 48-h contact diaries that epidemiologists have used in recent national surveys for modeling the spread of infectious diseases (Mossong et al., 2008; Kretzschmar and Mikolajczyk, 2009; Hens et al., 2009; Read et al., 2012).

If carried out and supervised carefully, collecting contact diaries can be a direct and more extensive method to measure egocentric network by eliciting all kinds of different ties. Despite the risks and limits of the diary method - such as sampling, small number of respondents, time consumption, fatigue and expenses - the contacts and ties recorded tend to be more diversified. In short, diary data yield very useful information and help capture a whole range of strength of ego-alter ties that no other generators can offer (Chua et al., 2011). Longitudinal contact diaries in greater detail can further facilitate analyses of novel research issues, such as how time investment in daily contacts yields immediate returns (Fu, 2008), or how the effects of tie strength on instrumental and affective gains vary by contact initiation (Fu et al., 2013).

Contact diaries thus far have been limited to case studies in a single country, however, and most of these studies focus only on a specific group of respondents. For example, earlier contact diaries were collected in the United States on a college campus (Gurevitch, 1961; de Sola Pool and Kochen, 1978), then in Russia from a group of school teachers (Lonkila, 1999). More recent diary studies targeted people of various backgrounds, but was also limited to a single society (Fu, 2005, 2007). As informative and inspiring as these diary studies can be, their designs may differ sharply and the resulting contact records are rarely compatible, thus preventing cross-national comparisons to this date. Our study aims to bridge this gap with two sets of diary data collected in two countries using nearly identical instruments.

\section{Data and methods}

We screened data from 54 Taiwanese and 142 Hungarian weeklong diaries for our comparative studies. Although the instruments were very similar to each other, the data were collected in different years with some differences in research designs, which must be taken into account when comparing them in subsequent analyses.

\subsection{Taiwan}

We first conducted a diary study in 2004. Sixty-two adults initially were recruited from two different sources: one from respondents in a national probability survey, and the other from snowball sampling started by nationwide survey fieldworkers. After 3 months, 54 of these informants had completed the diaries (the process was explained in greater detail in Fu, 2007). The sample is too small to be representative, with females, younger adults, and the better-educated being somewhat overrepresented. In terms of basic socio-demographic background, however, the diversity of the sample allows analyses that unveil group differences.

Taiwan's contact diaries targeted all kinds of social interactions with a wide variety of people. We gave all diary keepers clear instructions, both written and oral, on different occasions: "Please record all one-on-one interpersonal contacts by all means of communications, including nodding, saying hello, chatting, and discussion, whether you know the contacted persons or not." Diarykeepers were also asked to record multiple contacts with the same person that occurred on the same day. For example, if the diary keeper talked to someone over the phone in the morning, then met with the same person later in the afternoon, these two contacts "were recorded as separate entries. Such a design allows us to distinguish different circumstances under which the contacts take place" (Fu, 2005:174).

The content of Taiwan's contact diaries was broad. In the diary log, each ego recorded 27 items for every single contact, including (1) alter's demographic and socioeconomic characteristics, such as gender, age, occupations, and so on; (2) the circumstances of contacts, such as form, content, location, audience, duration, contact initiation, and subjective evaluation of the outcomes; (3) the relationship between ego and alter, such as contact frequency, duration of acquaintanceship, and closeness, as well as affective ties with alter (Fu, 2005, 2007). With such comprehensive information about alter, contact situations, and the ego-alter ties, we are able to analyze the egocentric "contact networks" from the perspectives of individual, tie, and contact.

\subsection{Hungary}

With similar research purposes in mind, we recruited respondents from a panel survey conducted in Nyiregyhaza, a town in northeastern Hungary with about 120,000 residents. All respondents were older than 18 and were chosen by random sampling. The original panel sample was representative in gender, containing 2000 residents, with a supplemental sample of 400 more inhabitants.

The Hungarian diary study was conducted in two phases. First, 400 people were selected independently from the survey respondents to keep contact diaries for one week. After one week, 67 respondents completed the diaries. Then more survey respondents were recruited with similar criteria to be representative in gender. As a result, 75 more diaries were collected, adding up to a total of 142 weeklong diaries (Huszti et al., 2013). Like Taiwan's instrument, the Hungarian contact diaries were also self-administered. In addition to an initial face-to-face introduction, trained interviewers provided assistance throughout the data-collection process. Other procedures of data collection followed that of Taiwan's diary study (Fu, 2007).

The Hungarian contact diaries also include those saying hello, chatting, talking, sending or receiving a message, and the contacts that occurred face-to-face, over the phone, on the Internet 
or by other means of communication. To lower respondents' burden of diary keeping, however, the diary covered only one-to-one contacts that lasted for at least $5 \mathrm{~min}$, or brief contacts that respondents considered important. Each diary log was divided into three periods (morning, afternoon, and evening) to allow easier recording of names and contacts. No matter how many times a person was mentioned in the diary (i.e., more than once a day or week), each ego needed to answer the questions about that person's background information only once. Each entry of the diary log included 15 question items about the contact situations.

In sum, the two original diary studies differ in two aspects that may need adjustments in subsequent analyses. First, respondents in Taiwan kept contact diaries for three consecutive months, while those in Hungary kept them for only one week. Second, we set no lower limit for the duration of contact for Taiwan, but the Hungarian diary keepers were instructed to record any contacts that lasted for at least $5 \mathrm{~min}$, or other contacts that were significant to them. To make our data as comparable as possible, we took several control measures to minimize any possible ill effects of such discrepancies between the two samples.

\subsection{Cross-national samples: ego-level characteristics}

To construct more compatible diary data from the two countries, we extracted the first week's data from Taiwan's 3-month contact diaries to match the Hungarian weeklong diaries. After screening for diary data sets that were completed with unique and identifiable alter names, we used diaries from 51 Taiwanese and 138 Hungarian respondents for comparisons and further analyses. In addition to data on the ego level, these diaries generate information about 2609 Taiwanese and 2335 Hungarian ego-alter ties. In the following sections, we start with a summary of ego-level characteristics in both samples, then use alter and ego-alter ties as the units of analyses for comparisons in the size and composition of egocentric networks.

Table 1 lists the distribution of respondents' sociodemographical characteristics. The diary samples at the ego level in both countries resemble each other in terms of gender composition: $58.8 \%$ of the Taiwanese sample and $58.0 \%$ of the Hungarian sample are female. In both samples, the rates of those who completed secondary education $(60.8 \%$ and $60.2 \%$, respectively) are also nearly equal. More Hungarian than Taiwanese respondents received only elementary-school education, while in Taiwan respondents with higher education are overrepresented.

The socio-demographic background characteristic that differed the most between the two samples was age distribution. More of the Taiwanese respondents were younger when they kept the diaries: $94 \%$ of them were below age 50, while in Hungary only $61 \%$ were younger than that age. In contrast, only one Taiwanese respondent $(2.0 \%$ ) was older than 60 , but more than one-fifth of the Hungarian respondents (21.8\%) were over that age.

\section{Network size and composition}

The contact networks built over one week are by no means comprehensive, but the diary data give some preliminary indications. As listed in Table 1, our initial cross-national comparison of the contact network size is based on the average number of alters named in one week. The most obvious difference is in the sheer numbers of alters recorded in the two countries. During the 7-day period, 51 Taiwanese respondents named 2609 alters altogether, but the total number of alters named in the 138 Hungarian weeklong diaries was only 2335 . Even with nearly three times as many contact diaries as their Taiwanese counterparts, the Hungarian respondents had fewer total contacts in one week.
Table 1

Egos' background and the numbers of contacted alters.

\begin{tabular}{|c|c|c|c|c|}
\hline & \multicolumn{2}{|c|}{ Taiwan } & \multicolumn{2}{|c|}{ Hungary } \\
\hline & $N$ & $\%$ & $N$ & $\%$ \\
\hline \multicolumn{5}{|l|}{ Gender } \\
\hline Male & 21 & 41.2 & 58 & 42.0 \\
\hline Female & 30 & 58.8 & 80 & 58.0 \\
\hline Total & 51 & 100.0 & 138 & 100.0 \\
\hline \multicolumn{5}{|l|}{ Age } \\
\hline $20-29$ & 11 & 21.6 & 26 & 19.5 \\
\hline $30-39$ & 23 & 45.0 & 32 & 24.2 \\
\hline $40-49$ & 14 & 27.5 & 24 & 18.0 \\
\hline $50-59$ & 2 & 3.9 & 22 & 16.5 \\
\hline $60-69$ & 1 & 2.0 & 29 & 21.8 \\
\hline Total & 51 & 100.0 & 133 & 100.0 \\
\hline \multicolumn{5}{|l|}{ Education } \\
\hline Elementary or lower & 1 & 2.0 & 12 & 9.0 \\
\hline Secondary & 31 & 60.8 & 80 & 60.2 \\
\hline Higher education & 19 & 37.2 & 41 & 30.8 \\
\hline Total & 51 & 100.0 & 133 & 100.0 \\
\hline \multicolumn{5}{|l|}{ Marital status } \\
\hline Single & 13 & 25.5 & 45 & 33.1 \\
\hline Married & 38 & 74.5 & 91 & 66.9 \\
\hline Total & 51 & 100.0 & 136 & 100.0 \\
\hline \multicolumn{5}{|c|}{ Numbers of contacted alters } \\
\hline Average & \multicolumn{2}{|c|}{51} & \multicolumn{2}{|r|}{17} \\
\hline S.D. & \multicolumn{2}{|c|}{28} & \multicolumn{2}{|r|}{12} \\
\hline Minimum & \multicolumn{2}{|c|}{14} & \multicolumn{2}{|r|}{1} \\
\hline Maximum & \multicolumn{2}{|c|}{140} & \multicolumn{2}{|r|}{93} \\
\hline Total & \multicolumn{2}{|c|}{2609} & \multicolumn{2}{|r|}{2335} \\
\hline
\end{tabular}

Given the big difference between the two samples in the total numbers of contacted alters in one week, it is not surprising that the average weeklong Hungarian contact network size (17) was also significantly smaller than that of the Taiwanese (51). Some signs of social isolation are evident among the Hungarian respondents: for example, a Hungarian woman named only one alter with whom she had contact during the whole week, and $25 \%$ of the Hungarians had contact with fewer than 10 people.

The striking difference appears to be partly due to the slight discrepancy in the operational definitions of the "contacts" to be recorded, or different age and education structures of the samples. In our research design, however, we tried to control for some of the most obvious biases. On the one hand, even though the lower cut-off point of contact duration was $5 \mathrm{~min}$ in the Hungarian diary study, the respondents also recorded those contacts that lasted shorter than 5 min but were considered important to them. This practice would have helped include brief and fleeting contacts with important alters in the Hungarian diaries. On the other hand, while the Taiwanese respondents recorded everyone with whom they had contact during the week, in our analyses, we only include those alters whom ego could identify and name. Thus, even though in the original design all strangers and those with fleeting contacts were recorded, in the current study we have practically excluded strangers, unnamed, and unidentifiable persons from our data. In other words, even though our diary studies were not totally compatible, we have taken various control measures to make the criteria of alters as compatible as possible in the two countries.

The different age and education structures may also partially explain why network size varied so greatly across countries. In Hungary, as elsewhere, the elderly and the less educated are more excluded socially. They generally do not meet many people, and their network size clearly shrinks (Albert and Dávid, 1999, 2007). Because older and less educated respondents are significantly more represented in the Hungarian sample, this may play an important role in the big gap between the two countries. 
Table 2

Regression of contact network size.

\begin{tabular}{lll}
\hline Independent variables & Model 1 & Model 2 \\
\hline Male & $-3.430(3.595)$ & $-3.297(2.781)$ \\
Age group & $-2.391(1.340)$ & $0.581(1.072)$ \\
Education & $4.189(3.149)$ & $3.085(2.438)$ \\
Taiwan (base = Hungary) & - & $33.998(3.133)^{* * *}$ \\
Constant & $25.510(9.007)^{* * *}$ & $9.981(7.113)$ \\
$N$ & 178 & 178 \\
Adj. $R^{2}$ & 0.022 & 0.415 \\
\hline
\end{tabular}

Note: Standard errors are in parentheses.

$* p<.05$.

${ }^{* *} p<.01$

*** $p<.001$.

When we controlled for age and education level in either Analysis of Variance or Regression on network size, however, the overall difference between the two countries remained highly significant $(p<.001)$. In fact, the country variable alone accounted for nearly one half of the total variance explained $\left(\eta^{2}=0.427\right.$, Appendix A). Likewise, in multivariate regression analyses, gender, age, and education combined to explain about only $2.2 \%$ of why the size of contact networks varied among the respondents in two countries (Table 2, Model 1). When taking the country variable into account, that proportion of the explained variance also jumped sharply to $41.5 \%$ (Table 2, Model 2). Thus, even though individual characteristics may help explain why contact networks vary among respondents, the difference between the two countries remains too large to ignore.

Previous cross-cultural studies have noted the small, sparse, and less supportive nature of Hungarian personal networks (Höllinger and Haller, 1990; Albert and Dávid, 2007). Whether it is personal experiences (Kornai, 2006) or social network surveys conducted in other former communist countries (Völker and Flap, 2001), empirical studies suggest that 25 years, the amount of time that has passed since the fall of communism, are simply not enough to bring about certain changes in the main structure of personal networks. In ex-socialist countries, weak ties remain difficult to establish and egocentric networks are hard to expand, particularly among certain socio-demographic groups (e.g., older people, the less educated, or rural residents). In addition, 15 years after the Transition the level of general trust was still low and limited. In fact, more than two third of respondents felt that the level of general trust had even decreased, while close family and friends were the only people to seek help from when facing any problems, or to whom they could disclose personal matters (Kopasz et al., 2008).

When we compare the average network sizes by respondents' socio-demographic characteristics, other differences seem to exist as well (Table 3). All of the three socio-demographic characteristics (gender, age, education) have quite different effects in the two countries. While women (57) have larger networks than men (43) in Taiwan, the average sizes of women's and men's networks are

Table 3

Average numbers of alters by socio-demographics.

\begin{tabular}{lll}
\hline & Taiwan & Hungary \\
\hline Gender & & \\
$\quad$ Male & 43 & 17 \\
Female & 57 & 17 \\
Age & & \\
$18-29$ & 38 & 20 \\
$30-39$ & 45 & 19 \\
40 and more & 69 & 15 \\
Education & & \\
$\quad$ Secondary school or lower & 56 & 15 \\
$\quad$ Higher education & 44 & 23
\end{tabular}

Table 4

Types of alter's relationships to ego.

\begin{tabular}{|c|c|c|c|c|}
\hline \multirow[t]{2}{*}{ Types of relationships } & \multicolumn{2}{|c|}{ Taiwan } & \multicolumn{2}{|c|}{ Hungary } \\
\hline & $N$ & $\%$ & $N$ & $\%$ \\
\hline Spouse & 38 & 1.5 & 71 & 3.1 \\
\hline Parent & 53 & 2.0 & 131 & 5.7 \\
\hline Child & 48 & 1.8 & 138 & 6.0 \\
\hline Sibling & 72 & 2.8 & 99 & 4.3 \\
\hline Immediate family & $(211)$ & $(8.1)$ & $(439)$ & $(19.1)$ \\
\hline Other kin (extended family) & 286 & 11.0 & 316 & 13.6 \\
\hline Family and relative & 497 & 19.1 & 755 & 32.7 \\
\hline Neighbor & 192 & 7.4 & 232 & 10.0 \\
\hline School (classmate, teacher) & 173 & 6.7 & 113 & 4.9 \\
\hline Colleague & 621 & 23.9 & 367 & 15.9 \\
\hline Other work-related & 288 & 11.1 & 139 & 6.0 \\
\hline Close friend & 198 & 7.6 & 342 & 14.8 \\
\hline Acquaintances & 394 & 15.2 & 16 & 0.7 \\
\hline Club members/service workers & 162 & 6.2 & 246 & 10.6 \\
\hline Others & 75 & 2.9 & 101 & 4.4 \\
\hline Non-kin & 2103 & 80.9 & 1556 & 67.3 \\
\hline Total number of alters & 2600 & 100.0 & 2311 & 100.0 \\
\hline
\end{tabular}

virtually the same (17) in Hungary. Network size remains similar across the three age groups in Hungary, except for a small decrease among those over 40 years old. In contrast, network size in Taiwan increases from those in their 20s and 30s to those in their 40s and older. As shown in Table 1, only 17 Taiwanese respondents (33.4\%) were over age 40 compared to nearly $56.3 \%$ in the Hungarian sample. Thus one should be cautious about associating network size with age in any linear terms. Our diary data show that Taiwanese egocentric networks tend to expand as people head to their midage careers or life cycles. After that stage, our ego-level sample size was too small to indicate any trend.

Like age structure, education level also seems to play a different role in the two countries. In Hungary the higher-educated respondents had larger contact networks. As other studies have indicated (Albert and Dávid, 1999, 2007), while the number of family, relatives, and strong ties are similar among people with different education levels, the better-educated tend to have many more non-kin contacts, such as colleagues, friends, and acquaintances. This pattern appears to be opposite to that in Taiwan. On average, those college-educated respondents have fewer contacts during the week. Nonetheless, such a pattern differs from other findings using large representative survey data (Fu, 2005). Once again, due to the small number of egos in Taiwan's contact diaries, particularly those with higher education, the finding here remains tentative.

In addition to network size, the two samples also differ in network composition in terms of the role relationships. We classified all ego-alter ties into following relationships: spouse, parent, child, sibling, other kin, neighbor, school relations (classmates, teachers), colleagues, close friends, acquaintances, other work-related, club members or service workers, and others. The first four types are further grouped into "immediate family."

The immediate family comprises about $19.1 \%$ of all alters in the Hungarian weeklong contact diaries, while only $8.1 \%$ in Taiwan (Table 4). This large difference reflects two sides about the role of immediate family in the two countries. On the one hand, because there are 138 Hungarian respondents and only 51 Taiwanese counterparts, the average number of immediate family members for each ego in Hungary (3.2) is slightly lower than that in Taiwan (4.1). On the other hand, due to much smaller contact networks in Hungary, the immediate family actually plays a larger role there in quantitative terms. In comparison, the percentage of other kin members is only slightly higher in Hungary (13.6\%) than in Taiwan $(11.0 \%)$. 
Taking into account all contacted alters beyond family and relatives, then, Taiwanese respondents have contact with more non-kin alters (with a higher percentage at $80.9 \%$ ) than Hungarians (67.3\%). In particular, colleagues and other work-related alters (such as clients) comprise a more significant percentage in Taiwan (35.0\%) than in Hungary (21.9\%). On average, the Taiwanese contact with 4.5 times more colleagues than the Hungarians (12.2 versus 2.7). Similarly, there is a huge, 5.7-fold gap between the numbers of other work-related contacts mentioned in the diaries: 5.7 in Taiwan versus 1.0 in Hungary. Most of all, about 15\% of alters in Taiwan's sample are acquaintances, compared to a mere $1 \%$ in Hungary. The Hungarians hardly mentioned any acquaintances ( 0.1 per ego), while the Taiwanese listed 7.7, on average. In this case only, we could suspect that the duration of the contact had influenced the responses: In Hungary, a contact not valued as important and lasting less than $5 \mathrm{~min}$ in duration was not to be listed, while in Taiwan no such qualification was used.

These differences partly reflect the fact that Taiwanese respondents have contact with many more alters in the week, which include a significant proportion of non-kin and other people who are not specifically related to egos, including many weakly tied acquaintances. Nevertheless, even close friends appear to play a bigger role in Taiwan: on average, Hungarians had contact with 2.5 close friends during the week, but Taiwanese had contact with 3.9 close friends. In sum, the weeklong contact networks in Taiwan reveal a significantly more active social life than such networks in Hungary.

\section{Strength of Tie (SoT) index}

The cross-national comparisons show significant differences in network size and composition, even after controlling for differences in socio-demographic background. To further examine egocentric contact networks in the two countries, we use four indicators that often represent different dimensions of tie strength in crossnational comparisons. Two of the indicators represent objective measures of ties: the frequency of contact reported by ego, and the number of days when ego had contact with the identical alter. The other two indicators measure tie strength by how ego evaluated each alter or ego-alter tie subjectively: how much ego liked alter and how close ego believed the tie to be. Together, the four indicators allow a multidimensional approach that covers the fundamental components of tie strength (particularly frequency of interactions, intimacy, and emotional intensity, see Granovetter, 1973, 1974; Hite, 2003, 2005, 2008; Marsden and Campbell, 2012). Among the four indicators, frequency of contact and subjective closeness are among the most common measures in the literature.

\subsection{Four indicators}

The first two indicators assess how frequently ego and alter interact with each other: one by a self-reported question item, and the other by calculating the number of days in the week when the two parties contact each other. While the first is often used as a basic indicator for tie strength, the answers are self-reported and are subject to the respondent's judgments. In contrast, the second indicator reflects the contact that ego records every day during the week. The third and the fourth indicators represent two important affective aspects: how much ego likes alter, and how intimate the ego-alter relationship is.

In total, we rely on six questions from the contact diaries that are compatible across the two samples. The first indicator is ego's report of how often ego and alter have face-to-face communication, ranging from "never or seldom" (pooled from two separate categories in Taiwan's diaries) and "sometimes" to "often." For the
Table 5

Indicators of the strength of ego-alter ties.

\begin{tabular}{|c|c|c|c|c|}
\hline \multirow[t]{2}{*}{ Indicators } & \multicolumn{2}{|c|}{ Taiwan } & \multicolumn{2}{|c|}{ Hungary } \\
\hline & $N$ & $\%$ & $N$ & $\%$ \\
\hline \multicolumn{5}{|c|}{ 1. Freq. of face-to-face contacts } \\
\hline Never or seldom & 473 & 18.3 & 396 & 17.1 \\
\hline Sometimes & 889 & 34.3 & 865 & 37.3 \\
\hline Often & 1228 & 47.4 & 1055 & 45.6 \\
\hline Total & 2590 & 100.0 & 2316 & 100.0 \\
\hline \multicolumn{5}{|c|}{ 2. Days contacted during the week } \\
\hline 1 & 1563 & 59.9 & 1376 & 58.6 \\
\hline 2 & 424 & 16.3 & 320 & 13.7 \\
\hline 3 & 211 & 8.1 & 164 & 7.0 \\
\hline 4 & 144 & 5.5 & 127 & 5.4 \\
\hline 5 & 126 & 4.8 & 102 & 4.4 \\
\hline 6 & 45 & 1.7 & 63 & 2.7 \\
\hline 7 & 96 & 3.7 & 192 & 8.2 \\
\hline Total & 2609 & 100.0 & 2344 & 100.0 \\
\hline \multicolumn{5}{|c|}{ 3. How much ego likes alter } \\
\hline Not at all & 20 & 0.8 & 24 & 1.0 \\
\hline A little & 208 & 8.1 & 94 & 4.0 \\
\hline Somewhat & 1565 & 60.6 & 1318 & 56.7 \\
\hline Very much & 787 & 30.5 & 890 & 38.3 \\
\hline Total & 2580 & 100.0 & 2326 & 100.0 \\
\hline \multicolumn{5}{|c|}{ 4. Closeness between ego and alter } \\
\hline Not at all & 136 & 5.2 & 194 & 8.3 \\
\hline A little & 1133 & 43.5 & 890 & 38.2 \\
\hline Somewhat & 896 & 34.3 & 668 & 28.6 \\
\hline Very much & 444 & 17.0 & 580 & 24.9 \\
\hline Total & 2609 & 100.0 & 2332 & 100.0 \\
\hline
\end{tabular}

second indicator, we calculate the number of days (ranging from 1 to 7 ) on which ego has contact with each specific alter. For the third indicator, we use a four-point scale to indicate how much ego likes alter, from "not at all" and "a little" to "somewhat" and "very much."

The fourth indicator, degree of intimacy between ego and alter, is a composite measure derived from three dummy variables. We decided how intimate a tie was by determining three conditions: whether the contact took place at either ego's or alter's home, whether the contact occurred face-to-face, and whether ego thought of alter as someone important or very important. The resulting degree of intimacy follows a four-point scale, where the minimum value is 0 , that is, none of the above criteria fulfilled, and the maximum is 3 , that is, when all of them are true. Therefore, 0 means the relationship is not intimate at all, and 3 means it is very intimate.

\subsection{Cross-national similarity in tie strength}

Despite of the above-mentioned cultural and social differences, the distributions of these four indicators turn out to be quite similar between Taiwan and Hungary. First of all, nearly one half of the egoalter ties maintain face-to-face contacts that are "often" in ego's view (47.4\% in Taiwan and 45.6\% in Hungary, Table 5), while fewer than $20 \%$ of the ties maintain no more than "seldom" face-to-face contact (18.3\% in Taiwan and $17.1 \%$ in Hungary). The diary records show that almost the same percentage of alters appear on only one day of the week in both Taiwan (59.9\%) and Hungary (58.6\%). In other words, $41.3 \%$ of the ego-alter ties in Hungary maintain contact more than weekly (at least two days during the week), only slightly higher than that in Taiwan (40.1\%).

Even the two subjective indicators seem to converge between the two samples. In Hungary about $95.0 \%$ of alters are someone that egos "like somewhat" or "like very much," also only slightly higher than that in Taiwan (91.1\%). A little more than one half (51.3\% in Taiwan and 53.5\% in Hungary) of the ego-alter ties also 
appear "somewhat" or "very much" intimate to egos. In sum, the ego-alter ties in the two diary studies show converging patterns of the strength of ego-alter ties.

The preliminary findings about such similar patterns on tie strength are noteworthy, given the following circumstances. First, the two countries differ from each other significantly in terms of social and cultural aspects. Second, network size and compositions also differ between the two countries markedly. Third, the cross-national differences are quite small across all four indicators, be they self-reported assessment of objective facts, active contact records, or affective measures.

\subsection{A composite index of tie strength}

To further compare tie strength between the two countries, we construct a composite, continuous Strength of Ties (SoT) index based on the four indicators. Although the studies of tie strength have progressed vastly during the past three decades, to our knowledge no cross-national studies have systematically defined the strength of ties on a continuous scale with the application of a multidimensional approach (Hite, 2003, 2005, 2008; Petróczi et al., 2007; Marsden and Campbell, 2012). Our cross-cultural, compatible data of contact diaries enable us to construct such an index that combines both objective and subjective measures, as well as self-assessment and contact records.

We created the composite SoT index using principal component analysis (Appendix B). According to this model, about 49 percent of the total variance was explained, and the lowest communality reached 0.445 . The resulting index is a standardized score. One of the main advantages of the index lies in its capability to measure tie strength not in a dichotomy but rather as a continuum - the higher the value, the stronger the tie. The mean value of the SoT index is -0.1 among the Taiwanese ego-alter ties, and 0.7 for the Hungarian sample.

With such a continuous index, we are able to first rank the types of ego-alter relationships by tie strength, then compare the findings between the two countries. In particular, by differentiating tie strength among different kin ties and among various non-kin ties, we can unravel variations within the dichotomous kin/nonkin ties that have been conventionally applied to be equivalent to tie strength. Moreover, the index allows us to compare how respondents from the two countries converge or diverge in maintaining ties with those who interact with them by various social relationships in everyday life.

\subsection{Tie strength by role relationships}

Overall, tie strength varies by the role relationships in similar patterns across the two countries. The continuous SoT index allows us to gain a clear picture of how each role relationship measures up in terms of the overall strength of ties. Most obviously, respondents in both countries clearly maintain strong ties, i.e. the ties that are stronger than average, with spouse, child, parent, sibling, and other kin members, in that order. The ties with immediate family members (spouse, child, and parent) are particularly strong. The only type of non-kin relationship that also maintains strong ties is close friends. In contrast, all other non-kin alters (classmate, colleague, teacher, work-related contacts, acquaintance, and others) maintain weaker-than-average ties with egos, with the exception of neighbors, who also have slightly stronger-than-average ties in Taiwan. Thus, in general, kin ties are indeed stronger than non-kin ties, with the exception of close friends (Fig. 1).

Although role relationships are ranked in a similar order in both countries in terms of tie strength, some gaps may indicate how Taiwanese and Hungarians interact with kin and non-kin members a little differently in everyday life. In both countries, spouse, child, parent, and sibling rank as the top four groups that are closely tied. This rank order is straightforward, and the gap between each group is clearly marked in Hungary. The ranking is less clear in Taiwan, however. In particular, the Taiwanese appear to be tied to their children as strongly as they are tied to spouse. While the tie with spouse is obviously the strongest for the Hungarians, child also plays such an equally pivotal role for the Taiwanese.

Another difference lies in the strength of ties with other kin members. In Hungary, kin members beyond the immediate family are nearly "neutrally tied," with an average SoT score of 0.02 . In contrast, the Taiwanese maintain much stronger ties with other relatives. Whereas relatives are not tied to the Hungarians as strongly as close friends, for the Taiwanese, relatives appear to be closer and more important than "close friends." In other words, kin members are significant in Hungarians' everyday lives to the extent that close friends play a little more important role than the relatives beyond immediate family. In Taiwan, however, ties with family and relatives are all clearly stronger than non-kin ties; not even close friends maintain more frequent and intimate contacts than extended kin ties.

In addition, the ties with other non-kin alters are all below the average composite score, except neighbors in Taiwan. Such generally weaker non-kin ties, however, still differ between the two countries in subtle ways. The differences in ranking include workrelated contacts, other non-kin relationships, and acquaintances. Other non-kin relations are the last in the scale for the Taiwanese, whereas acquaintances, normally referred to those without specific relationships, are the weakest ties in Hungary. This very last difference may again verify that our slightly narrower criteria to include alters in Hungary did not necessarily limit the Hungarian respondents to report only acquaintances they knew well. Even though less than $1 \%$ of the contacts that the Hungarians reported in their diaries were acquaintances, these acquaintances seemed to stretch to the outermost periphery of their contact networks where they maintained the weakest ties in everyday life.

To test the statistical significance of such differences in tie strength, we run regression analyses using an option of cluster in both countries. Because the SoT index is calculated from ego-alter ties reported or recorded by 51 diary keepers (egos) in Taiwan and 138 in Hungary, it is very likely that scores in each of four measures reported or evaluated by each ego may not be independent, which could lead to inter-dependent residuals within egos. To adjust for this potential bias, we use the cluster option to stipulate that the observations are clustered into egos. With such an adjustment, we compare tie strength of immediate family (including spouse, parents, children, and siblings), extended family (other kin members), and other ties against that of close friends (the base group).

First of all, the ties with immediate family are stronger compared to even close friends. Not only are the tests statistically significant in both countries ( $p<.001$, Models 1 and 2, Table 6$)$, but the sheer size of the regression coefficients is also large. In contrast, the ties with those who have no kin relationships are significantly weaker than those with close friends, a finding also consistent between Taiwan and Hungary $(p<.001)$. Extended family, or the relatives beyond the immediate family, however, plays very different roles in the two countries. In Taiwan, the ties with extended family are significantly stronger than that of close friends $(p<.01$, Model 1$)$; in Hungary, the ties with extended family and close friends are not clearly distinguishable. Thus, while it is generally true that our continuous SoT index helps identify stronger ties with kin members in both Taiwan and Hungary, in Hungary such strong kin ties actually refer to immediate family only. Beyond the immediate family, Hungarian kin members and close friends are about equally tied to ego. In Taiwan, all kin members are so strongly connected that even close friends are not as close as extended family members. 
Taiwan

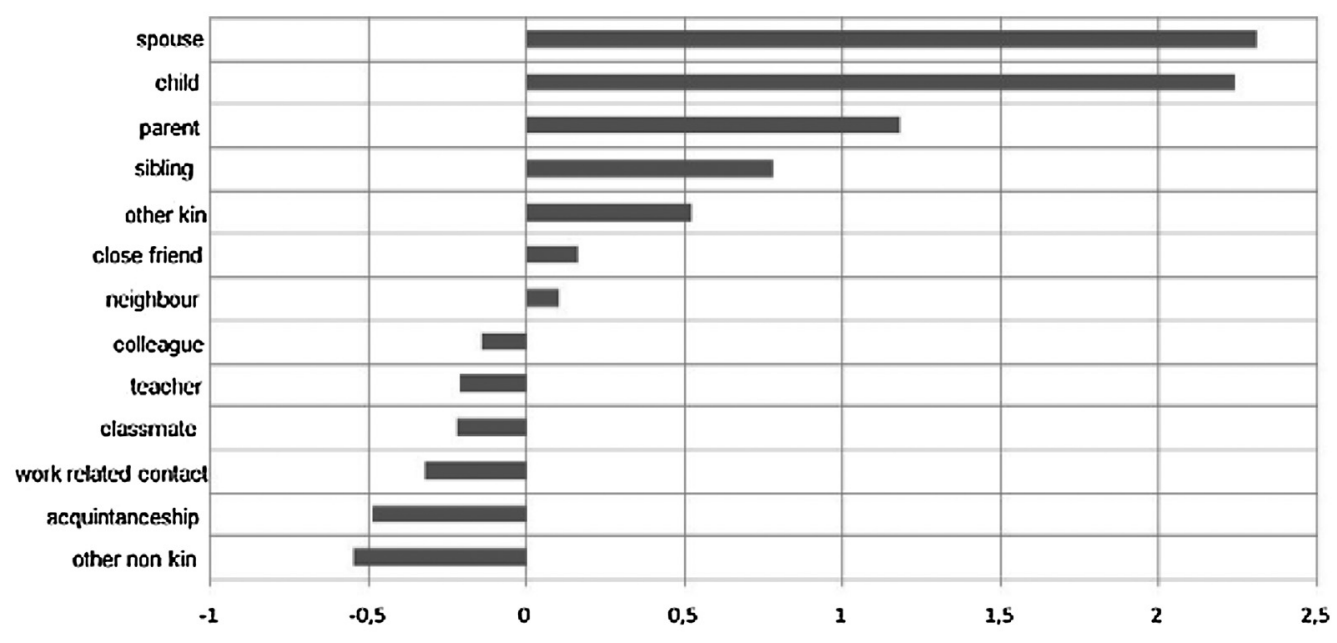

Hungary

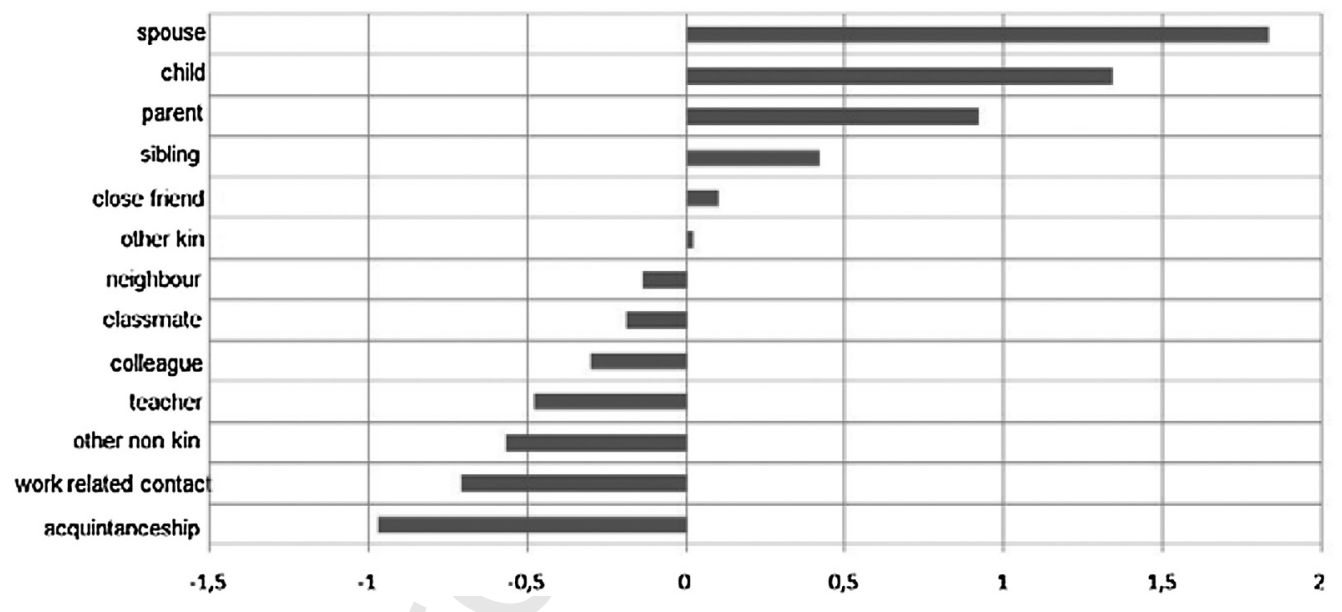

Fig. 1. The SoT index by types of relationships (mean).

Table 6

Regression of the strength of ego-alter ties (with cluster option).

\begin{tabular}{cll}
\hline Independent variables & $\begin{array}{l}\text { Model 1 } \\
\text { Taiwan }\end{array}$ & $\begin{array}{l}\text { Model 2 } \\
\text { Hungary }\end{array}$ \\
\hline Relationships (base = close friends) & & \\
$\quad$ Immediate family & 1.334 & 0.989 \\
Extended family & $(0.117)^{* * * *}$ & $(0.079)^{* * *}$ \\
Others/non-kin & 0.363 & -0.088 \\
& $(0.113)^{* * *}$ & $(0.087)$ \\
Constant & -0.418 & -0.518 \\
$N$ & $(0.085)^{* * *}$ & $(0.071)^{* * *}$ \\
$N$ & 0.156 & 0.100 \\
Adj. $R^{2}$ & $(0.067)^{*}$ & $(0.063)$ \\
\hline
\end{tabular}

Note: (1) Regression models are run using ego ( $n=51$ in Model $1, n=138$ in Model 2 ) as the clustering unit; (2) standard errors are in parentheses.

* $p<.05$.

*** $p<.01$.

*** $p<.001$.
When comparing such network compositions and tie strengths across the nations, it should be cautious not to confuse the content or implications of a certain relationship with that of the other. In particular, while the ties with the extended family in Taiwan and the ties with close friends in Hungary are both the strongest beyond one's immediate family circles, they may play different roles in the personal networks. Close friends in Hungary, for example, may offer strong emotional support. The extended family in Taiwan, as suggested in other studies, often provides institutional helps. It would be interesting to further explore the extent to which close friends give institutional helps, and how likely a relative also renders emotional support.

\section{Discussion and conclusion}

By linking national characteristics to everyday contact networks, our study showed that the two major macro-level forces we examined helped condition everyday contact patterns somewhat differently in Taiwan and Hungary. First, while close kin structures are obvious in both Taiwan and Hungary, the extended networks with relatives deriving from the Chinese kinship system 
remain particularly strong in Taiwan, a distinctive feature lacking in Hungary. Second, despite the shift from authoritarianism to democracy in both countries, the active networks in everyday life have not reached beyond the kinship circles extensively. The contact with those without a kinship tie remains particularly limited in Hungary.

During the second half of the 20th century, both Taiwan and Hungary shared the same authoritarian past before moving to Western-style democracies. One anti-communist in East Asia, the other communist in Eastern Europe, the two authoritarian regimes in the old days nonetheless exerted similarly strict and widespread political control over their citizens by severe martial-law enforcement, secret police, and police informers. The potential damages brought by casual leaks through weak ties and strangers discouraged connections with weakly tied others, thus yielding limited egocentric networks. After the both authoritarian regimes transformed into democracies, it would be intriguing to see if the limited non-kin ties are part of the enduring effects from the unfavorable political circumstances in the past.

As suggested by empirical findings from other former Sovietbloc Eastern European countries, weak ties remained a liability even after the Berlin Wall had fallen, because residents still refrained from openly communicating with strangers in public (Volker and Flap, 2001). Do any of the effects that resulted from avoiding contacts with weak ties and strangers in the old days also linger in Hungary? If citizens have access to free communication in both public and private spheres after nearly two decades of democratic governance and amid the boom of political parties, why are their daily contacts limited largely to kinship circles? In other words, is it possible that people maintain only their closest ties with kin and other close friends because weak ties remain a liability?

One of the strong indicators of "weak ties as a liability" phenomenon lies in the widespread distrust to general others. Although the current diary data offer no information about the linkage between distrust and personal networks, another comparative survey data, the 2006 module on Role of Government of the International Social Survey Programme, indicate how contacts in daily life may be reversely associated with the extent of distrust to general others. Compared to their Taiwanese counterparts, the Hungarian respondents in the ISSP survey reported fewer daily contacts and higher distrust level. When asked to estimate the range of the number of acquaintances with whom they have contact in a typical week day (q20 in the 2006 ISSP questionnaire, a rough yet reliable measure of personal networks, ranging from 1 to 5 , Appendix C; see also $\mathrm{Fu}, 2005)$, about $7.0 \%$ of the Taiwanese respondents chose "over 50 " and $18.2 \%$ picked "from 20 to 49 ", compared to only $3.8 \%$ choosing "over 50" and 8.3\% for "from 20 to 49" in Hungary. Further, while about $56.3 \%$ of the Taiwanese either agreed or strongly agreed that "There are only a few people I can trust completely" (item q13a in the 2006 ISSP questionnaire), $80.1 \%$ of the Hungarian counterparts revealed the similar sign of distrusting others (ISSP Research Group, 2008).

At first glance, the extent of daily contacts is negatively correlated with distrust in both Taiwan $(r=-.048, p<.05)$ and Hungary $(r=-.110, p<.001)$. Similar patterns can be further confirmed by ordered logistic regression. When their key sociodemographic factors (gender, age, urban-rural residence, education, work status, and self-rated social status) are taken into account, those who distrust other people tend to have fewer daily contacts in both countries. The Hungarian respondents, in particular, show a greater association between contacts and distrust. For every level up in the distrust item (which ranges from 1 to 5 after being recoded), the daily contact (also ranging from 1 to 5 ) will drop nearly 0.2 level $(p<.01$, Appendix $C)$. In sum, not only are the Hungarian respondents more prone to distrust people and to have fewer interpersonal contacts, but the distrust factor also plays a larger role in Hungary in explaining why people vary in the range of daily contacts. Thus, the Hungarians appear to be more limited in their daily contacts because distrust is more widespread.

Taking kinship systems into account on the one hand, and political developments on the other, the current study compared whether and how macro-level forces were linked to egocentric networks in Taiwan and Hungary with compatible data sets. With analyses based on both compatible contact diaries and the ISSP survey data, our findings could contribute to the existing literature on the relationship between societal characteristics and interpersonal ties. The two-society exploration also aimed to shed light on social network studies by using largely identical contact diaries with comparative perspectives.

Contact diaries enable network researchers to reconstruct active egocentric networks that help reveal detailed information at both tie and contact levels in everyday social interactions. The resulting contact networks enrich network analyses by adding active social interactions (Fu, 2007). Although past diary studies were limited to single countries, we conducted contact diaries in both Taiwan and Hungary that allowed us to compare basic network structures as well as the strength of ties, one of the widely used concepts in social networks (Marsden and Campbell, 1984, 2012). We started out the diary study in Taiwan and repeated data collection in Hungary, with modifications to smooth the diary keeping and accommodate a larger sample size.

According to their socio-demographic composition, the two samples of diary keepers converged in gender and marital status, while differed considerably in age and education level. The size of contact networks turned out to be significantly larger in Taiwan than in Hungary, which may be partly due to slight differences in methodology. Our findings are consistent with previous cross-national studies that relied on the same research instruments across different member countries.

On average, the number of alters contacted in a week (or the size of contact networks) is much larger in Taiwan than in Hungary, which remains unchanged after controlling for key sociodemographic background factors. Even though the four indicators that we use to construct the SoT index are similarly distributed among the respondents in both Taiwan and Hungary, the composite index pinpoints how the types of relationships play somewhat different roles across the nations. Our findings may contribute to the understanding of substantive research issues regarding egocentric networks in East Asian and Eastern European societies. Such exploratory cross-cultural comparisons also give broader empirical supports to the diary approach of social network studies, which helps better capture the subsets of egocentric networks that are active in everyday life.

Our cross-national and cross-cultural comparisons of the resulting compatible contact diaries yield important findings about egocentric contact networks. In particular, the four indicators of tie strength reveal very similar patterns of daily contacts between the two countries. Not only did the Taiwanese and Hungarians respondents report almost the same frequencies of contact, but they also had similar distributions of the number of days when they interacted with someone. Subjectively, they converged again in how well they liked or disliked the people with whom they had contact, and how close they felt to these people. It would be very interesting to examine whether such a pattern of tie strength also prevails in other countries should more compatible contact diaries become available.

The SoT index that we constructed from these four indicators allowed us to further compare tie strength by role relationships in continuous terms. As consistent with the descriptive statistics, all ties with immediate family members, particularly the spouse, turned out the strongest among all relationships in both countries. 
The ties with children were as strong as that with the spouse in Taiwan, however, which may be an everyday practice that reflects family values in different cultures. Extended kin members beyond the immediate family were also tied to the Taiwanese rather strongly, even stronger than that with close friends. Such strong extended kin ties were absent in Hungary, thus confirming another critical cross-national difference in kinship ties.

Our study extends the existing literature about egocentric networks in several ways. First, by comparing two countries that differ in kinship systems but both have transformed from strict authoritarian regimes to emerging democracies, the study examined whether and how institutional and macro-level forces may trickle down to egocentric networks at the individual level, and how such cultural traditions and structural influences may linger even after circumstances have changed. Second, while comparative studies of egocentric networks based on cross-national surveys have been fruitful, and case studies based on in-depth contact diaries have been inspiring, we expanded the diary studies by designing and collecting compatible contact diaries in an East Asian country and an Eastern European country.

Third, to align with mainstream egocentric network studies, our cross-national contact diaries also incorporated question items about tie strength often used in social surveys. As a result, we were able to examine network structures by means of both selfassessment and actual information about social interactions, which helped us construct the continuous SoT index on multidimensional scales. Even though the information was provided exclusively by our respondents, they kept the records about contacts in daily life on a continuous basis for one week, thus alleviating the potential biases often caused by one-shot surveys or experiments. As the case with cross-national comparisons using the SoT index, the same index can also be applied for within-nation comparisons, such as among social groups divided by age, gender, ethnicity, education, and so on.

One of the most significant challenges of the diary approach in general is how to keep a reasonable balance between sample size and the length of diary keeping. Because diary keeping imposes a demanding task on the average respondent, researchers usually focus on a small number of respondents. Given the rarity of contact diary studies, our cross-national comparisons used two of the largest diary studies in the literature. In total, we have combined and compared 189 sets of contact diaries. Few of the previous studies have exceeded this number of diaries: Gurevitch (1961) collected 18 diaries, de Sola Pool and Kochen (1978) used 27 diaries, Lonkila (1999) first gathered 78 diaries (only among teachers), followed by 20 diaries 2 years later, and $\mathrm{Fu}$ (2007) relied on 54 diaries. By contrasting contact diaries from East Asian and Eastern European countries, our comparative study somehow highlights East-West cultural differences in how contact networks function in everyday life.

Although a small sample often better accommodates longer diary keeping that in turn enables more sophisticated analyses, it is obviously an important limitation to keep in mind when generalization is at stake. In our comparative study between the two countries, we have further analyzed survey data from the ISSP to extend our discussions and strengthen research implications. Because such nationwide surveys typically rely on strict probability sampling schemes that yield large representative samples, the survey findings can be more easily inferred to the whole populations. With most cross-national surveys asking identical or very similar questions, moreover, these survey studies also tend to provide compatible results across nations or among various social groups.

In comparison, network analyses based on contact diaries help build active contact networks and can be less subjected to biases due to imprecise recalls or short-term variations. Because contact diaries require strong commitment from the diary keepers and can easily become a tedious task, the sample size of contact networks is typically small, making statistical inferences difficult. Given such strengths and weaknesses, is it possible to apply contact diaries to large-scale probability surveys, to open up new opportunities for merging the two seemingly opposing approaches?

Recent attempts by epidemiologists to collect $24-\mathrm{h}$ or 48 -h contact diaries in large-scale, representative national surveys may present a good possibility for network researchers to explore how to generalize findings from contact diaries to egocentric networks within the general population. Systematic analyses with national samples at this scale would further enrich studies of contact networks using comparative perspectives. Finally, in-depth comparative analyses across more countries that have experienced similar political and economic developments would further inspire the thinking about how social changes from the wider society may help condition and formulate egocentric networks.

\section{Uncited references}

Huszti (2011) and Lee et al. (2005).

\section{Acknowledgments}

Part of this study was supported by research grants from the National Science Council (grant nos. NSC95-2412-H-001-010-SSS, NSC100-2410-H-001-110-MY3) and Academia Sinica (grant no. AS-100-TP2-C01), Taiwan. An earlier version of the paper was presented at Sunbelt XXXIII, the Annual Meeting of the International Network for Social Network Analysis, in Hamburg, Germany, 2013. We thank H. Russell Bernard, Claude S. Fischer, Ray-May Hsung, Nan Lin, and Robert Tardos for extensive support and suggestions, and anonymous reviewers of the Journal for insightful comments.

Appendix A. Hierarchical ANOVA models: network-size differences in Taiwan and Hungary, uncontrolled and controlled for age-group and education

\begin{tabular}{|c|c|c|c|c|c|}
\hline & Sum of squares & df & Mean square & $F$ & Sig. \\
\hline Model 1 & & & & & \\
\hline $\begin{array}{l}\text { Country } \\
\text { (base = Hungary) } \\
\text { Taiwan }\end{array}$ & $43,648.37$ & 1 & $43,648.37$ & 139.243 & 0.000 \\
\hline \multicolumn{6}{|l|}{ Model 2} \\
\hline Age-group & 709.31 & 2 & 354.65 & 1.265 & 0.285 \\
\hline $\begin{array}{l}\text { Education } \\
\text { controlled for } \\
\text { age-group }\end{array}$ & 2067.99 & 2 & 1033.99 & 3.688 & 0.027 \\
\hline $\begin{array}{l}\text { Country } \\
\text { (Taiwan) } \\
\text { controlled for } \\
\text { age-group and } \\
\text { education }\end{array}$ & $40,497.83$ & 1 & $40,497.83$ & 144.448 & 0.000 \\
\hline
\end{tabular}

Appendix B. Factor loadings of Strength of Tie (SoT) index (principal component)

\begin{tabular}{lccc}
\hline & Both samples & Taiwan & Hungary \\
\hline Frequency of face-to-face contact & 0.680 & 0.656 & 0.710 \\
How much ego likes alter & 0.667 & 0.694 & 0.642 \\
Number of meeting during the week & 0.707 & 0.676 & 0.729 \\
Intimacy of the contact & 0.736 & 0.727 & 0.743 \\
Eigenvalue & 1.949 & 1.896 & 2.000 \\
\% of variance & 48.7 & 47.4 & 50.0 \\
\hline
\end{tabular}




\section{Appendix C. Ordered logistic regression of daily contacts (dependent variable $=$ daily contacts, $1-5$ )}

\begin{tabular}{|c|c|c|}
\hline Independent variables & Taiwan & Hungary \\
\hline Gender $($ male $=1$ ) & $0.110(.093)$ & $-0.010(.130)$ \\
\hline Age (18-97) & $0.032(.016)$ & $0.058(.023)^{*}$ \\
\hline Age squared & $0.000(.000)$ & $-0.001(.000)^{* * * *}$ \\
\hline Urban (1-4) & $-0.057(.043)$ & $-0.003(.053)$ \\
\hline Education (1-25) & $0.041(.015)^{* * *}$ & $0.050(.022)^{*}$ \\
\hline Work now $(=1)$ & $1.186(.118)^{* * * *}$ & $1.048(.163)^{* . *}$ \\
\hline Status $(1-10)$ & $0.031(.027)$ & $0.075(.047)$ \\
\hline Distrust (1-5) & $-0.088(.042)^{*}$ & $-0.199(.067)^{* *}$ \\
\hline _cut1 & $-0.456(.466)$ & $0.717(.683)$ \\
\hline _cut2 & $1.188(.466)^{*}$ & $2.123(.684)^{* *}$ \\
\hline _cut3 & $2.679(.470)^{* * *}$ & $3.500(.690)^{* . *}$ \\
\hline _cut4 & $4.266(.478)^{* . * * *}$ & $4.805(.706)^{* * * *}$ \\
\hline$N$ & 1614 & 898 \\
\hline Log likelihood & -2325 & -1081 \\
\hline Pseudo $R^{2}$ & 0.039 & 0.103 \\
\hline
\end{tabular}

Source: ISSP Research Group (2008).

Note: (1) Standard errors are in parentheses; (2) values for the dependent variable, daily contacts, are: $1=1-4$ persons, $2=5-9$ persons, $3=10-19$ persons, $4=20-49$ persons, $5=50$ persons or more.

$p<.05$.

$p<.01$.

$p<.001$.

\section{References}

Albert, F., Dávid, B., 1999. About friends. In: Kolosi, T., Tóth, I.Gy., Vukovich, Gy.(Eds.), Social Report 1998. Tárki, Budapest, pp. 270-293.

Albert, F., Dávid, B., 2007. Embert barátjáról. A barátság szociológiája (Birds of a Feather. Sociology of Friendship). Századvég Kiadó, Budapest.

Bakacsi, Gy., Takács, S., Karácsony, A., Imrek, V., 2002. Eastern European cluster: tradition and transition. J. World Bus. 37, 69-80.

Bernard, H.R., Johnsen, E.C., Killworth, P.D., McCarty, C., Shelley, G.A., 1990. Comparing four different methods for measuring personal social networks. Soc. Netw. 12 (3), 179-215

Bian, Y., Ang, S., 1997. Guanxi networks and job mobility in China and Singapore. Soc. Forces 75 (3), 981-1005.

Bian, Y., Ikeda, K., 2014. East Asian social networks. In: Alhaji, R, Rokne, J. (Eds.), Encyclopedia of Social Network Analysis and Mining. Springer.

Böröcz, J., Southworth, C., 1995. Kapcsolatok és jövedelem Magyarország 1986-87 (Contacts and income. Hungary 1986-87). Szociológiai Szemle 5 (2), 25-48.

Brewer, D.D., 2000. Forgetting in the recall-based elicitation of personal and social networks. Soc. Netw. 22 (1), 29-43.

Burt, R.S., 1984. Network items and the General Social Survey. Soc. Netw. 6 (4), 293-339.

Campbell, K.E., Lee, B.A., 1991. Name generators in surveys of personal networks. Soc. Netw. 13 (3), 203-221.

Chua, R.Y.J., Morris, M.W., Ingram, P., 2009. Guanxi vs networking: distinctive configurations of affect- and cognition-based trust in the networks of Chinese vs American managers. J. Int. Bus. Stud. 40, 490-508.

Chua, V., Madej, J., Wellman, B., 2011. Personal communities. In: Carrington, P., Scott J. (Eds.), Handbook of Social Network Analysis. Sage, London, pp. 101-116.

de Sola Pool, I., Kochen, M., 1978. Contacts and influence. Soc. Netw. 1 (1), 5-51.

Erickson, B., 1996. Culture, class, and connections. Am. J. Sociol. 102 (1), 217-251.

Erickson, B., 2004. The distribution of gendered social capital in Canada. In: Flap, H. Volker, B. (Eds.), Creation and Returns of Social Capital: A New Research Program. Routledge, London, pp. 27-50

Fischer, C., 1982a. To Dwell Among Friends. University of California Press, Berkeley. Fischer, C., 1982b. What do we mean by 'friend'? An inductive study. Soc. Netw. 3 (4), 287-306.

Freedom House, 2014. Freedom in the World. https://freedomhouse.org/ report-types/freedom-world\#.VFuDd8IW5L8

Freeman, L.C., Ruan, D., 1997. An international comparative study of interpersonal behavior and role relationships. L'Annee Sociol. 47 (1), 89-115.

Freeman, L.C., Thompson, C.R., 1989. Estimating acquaintanceship volume. In: Kochen, M. (Ed.), The Small World. Ablex, Norwood, NJ, pp. 147-158.

$\mathrm{Fu}$, Y.-c., 2005. Measuring personal networks with daily contacts: a single-item survey question and the contact diary. Soc. Netw. 27 (3), 169-186.

Fu, Y.-c., 2007. Contact diaries: building archives of actual and comprehensive personal networks. Field Methods 19 (2), 194-217.

$\mathrm{Fu}$, Y.-c., 2008. The immediate returns on time investment in daily contacts: exploring the network-overlapping effects from contact diaries. In: Hsung, R.M., Lin, N., Breiger, R. (Eds.), Contexts of Social Capital. Social Networks in Markets, Communities and Families. Routledge, Taylor and Francis Group, New York, London, pp. 327-348.
Fu, Y.-c., Ho, H.-C., Chen, H.M., 2013. Weak ties and contact initiation in everyday life: exploring contextual variations from contact diaries. Soc. Netw. 35 (3), 279-498 Gelfand, M.J., Bhawuk, D.P.S., Nishii, L.H., Bechtold, D.J., 2004. Individualism. In: House, R.J., Hanges, P.J., Javidan, M., Dorfman, P.W., Gupta, V. (Eds.), Culture, Leadership, Organizations: The GLOBE Study of 62 Countries. Sage Publications, pp. 437-512.

Granovetter, M., 1973. The strength of weak ties. Am. J. Sociol. 78 (6), 1360-1380.

Granovetter, M.S., 1974. Getting a Job: A Study of Contacts and Careers. Harvard University Press, Boston, MA.

Granovetter, M., 1983. The strength of weak ties: a network theory revisited. Sociol. Theory 1 (1), 201-233.

Granovetter, M., 1985. Economic action and social structure: the problem of embeddedness. Am. J. Sociol. 91 (3), 481-510.

Gurevitch, M., 1961. The Social Structure of Acquaintanceship Networks. Massachusetts Institute of Technology.

Haythornthwaite, C., 2002. Strong, weak, and latent ties and the impact of new media. Inf. Society 18 (5), 385-401.

Hens, N., Goeyvaerts, N., Aerts, M., Shkedy, Z., Van Damme, P., et al., 2009. Mining social mixing patterns for infectious disease models based on a two-day population survey in Belgium. BMC Infect. Dis. 9 (5).

Hite, J.M., 2003. Patterns of multidimensionality among embedded network ties: typology of relational embeddedness in emerging entrepreneurial firms. Strateg. Organ. 1 (1), 9-49.

Hite, J.M., 2005. Evolutionary processes and paths of relationally embedded network ties in emerging entrepreneurial firms. Entrep. Theory Pract. 29 (1), 113-144.

Hite, J.M., 2008. The role of dyadic multi-dimensionality in the evolution of strategic network ties. In: Baum, J.A.C., Rowley, T.J. (Eds.), Network Strategy. Advances in Strategic Management, vol. 25, pp. 133-170.

House, R.J., Hanges, P.J., Javidan, M., Dorfman, P.W., Gupta, V. (Eds.), 2004. Culture, Leadership, and Organizations: The GLOBE Study of 62 Societies. Sage Publications.

Höllinger, F., Haller, M., 1990. Kinship and social networks in modern societies: a cross-cultural comparison among seven nations. Eur. Sociol. Rev. 6 (2) 103-124.

Hsung, R.-M., Lin, N., Breiger, R. (Eds.), 2009. Contexts of Social Capital: Social Networks in Markets, Communities, and Families. Routledge Press, London, pp. 327-347.

Huszti, É., 2011. From sociometry to network diary. Measuring personal networks Acta Med. Sociol. 2 (2), 129-141.

Huszti, É., David, B., Vajda, K., 2013. Strong tie, weak tie and in-betweens: a linear measure of tie strength based on network diary datasets. Procedia Soc. Behav. Sci. 79 (6), 38-61.

ISSP Research Group, ZA4700 Data file Version 1.0.0 2008. International Social Survey Programme: Role of Government IV - ISSP 2006. GESIS Data Archive, Cologne, http://dx.doi.org/10.4232/1.4700.

Kadusin, C., 2012. Understanding Social Networks: Theories, Concepts, and Findings. Oxford University Press, Oxford.

Killworth, P.D., Bernard, H.R., 1978. The reverse small-world experiment. Soc. Netw 1 (1), 159-192.

Killworth, P.D., McCarty, C., Johnsen, E.C., Bernard, H.R., Shelley, G.A., 2006. Investigating the variation of personal network size under unknown error conditions. Sociol. Methods Res. 35 (1), 84-112.

Kopasz, M., Szántó, Z., Várhalmi, Z., 2008 A magyar háztartások tagjainak kapcsolatháló-dinamikája 1992 és 2007 között. In: Kolosi, T., Tóth, I.Gy. (Eds.) Újratervezés. Életutak és alkalmazkodás a rendszerváltás évtizedeiben (Redesign: Walk of Lives and Adaptation in Decades of Transition). Tárki Press, Budapest, pp. 105-120.

Kornai, J., (translated by McLean, B. A gondolat erejével: Rendhagyó önéletrajz. Osiris, Budapest 2005 2006. By Force of Thought: Irregular Memoirs of an Intellectual Journey. MIT Press, London and Cambridge.

Kretzschmar, M., Mikolajczyk, R.T., 2009. Contact profiles in eight European countries and implications for modelling the spread of airborne infectious diseases. PLoS ONE 4 (6), e5931.

Laumann, E., 1973. Bonds of Pluralism: Form and Substance of Urban Socia Networks. Wiley, New York

Lee, R.P.L., Ruan, D., Lai, G., 2005. Social structure and support networks in Beijing and Hong Kong. Soc. Netw. 27 (3), 249-274.

Lin, N., Erickson, B. (Eds.), 2008. Social Capital: An International Research Program. Oxford University Press, Oxford.

Lin, N., Dumin, M., 1986. Access to occupations through social ties. Soc. Netw. 8 (4), 365-383.

Lin, N., Fu, Y.-c., Hsung, R.-M., 2001. The position generator: measurement techniques for investigations of social capital. In: Lin, N., Cook, K., Burt, R.S. (Eds.) Social Capital: Theory and Research. Aldine de Gruyter, New York, pp. 57-82.

Lin, N., Fu, Y.-c., Chen, C.-j.J. (Eds.), 2014. Social Capital and Its Institutional Contingency: A Study of the United States, China, and Taiwan. Routledge Press, London.

Lonkila, M., 1999. Social Networks in Post-Soviet Russia. Continuity and Change in the Everyday Life of St. Petersburg Teachers. Helsingin yliopistion verkkojulkaisut, Helsinki, ISBN 951-45-8742-1 (PDF version).

Marsden, P.V., 2003. Interviewer effects in measuring network size using a single name generator. Soc. Netw. 25 (1), 1-16.

Marsden, P.V., Campbell, K., 1984. Measuring tie strength. Soc. Forces 63 (2) 482-501.

Marsden, P.V., Campbell, K., 2012. Reflections on conceptualizing and measuring tie strength. Soc. Forces 91 (1), 17-23. 
Mathews, K.M., White, M.C., Soper, B., von Bergen, C.W., 1998. Association of indicators and predictors of tie-strength. Psychol. Rep. 83, 1459-1469.

McCormick, T.H., Salganik, M.J., Zheng, T., 2010. How many people do you know?: Efficiently estimating personal network size. J. Am. Stat. Assoc. 105 (489), 59-70.

Milgram, S., 1967. The small-world problem. Psychol. Today 1 (1), 61-67.

MOI (Ministry of the Interior, Republic of China), 2014. Monthly Bulletin of Interior Statistics. http://sowf.moi.gov.tw/stat/month/elist.htm

Molin, E., Arentze, T., Timmermans, H., 2008. Eliciting social network data. Paper presented at the International Conference on Survey Methods in Transport: Harmonisation and Data Comparability, May 25-31, France.

Mossong, J., Hens, N., Jit, M., Beutels, P., Auranen, K., et al., 2008. Social contacts and mixing patterns relevant to the spread of infectious diseases. PLoS Med. 5, e74.

National Election Office, Hungary, 2014. 2014 Parliamentary Elections, Available from: http://valasztas.hu/en/ogyv2014/index.html (accessed 7.11.14).

Petróczi, A., Nepusz, T., Bazsó, F., 2007. Measuring tie-strength in virtual social networks. Connections 27 (2), 39-52.

Read, J.M., Edmunds, W.J., Riley, S., Lessler, J., Cummings, D.A., 2012. Close encounters of the infectious kind: methods to measure social mixing behaviour. Epidemiol. Infect. 140 (12), 2117-2130.

Ruan, D., Freeman, L., Xinyuan, D., Yunkang, P., Wenhong, Z., 1997. On the changing structure of social networks in urban China. Soc. Netw. 19 (1), 75-89.

Spirova, M., 2008. Political Parties in Post-Communist Societies: Formation, Persistence, and Change. Palgrave Macmillan, New York.
Uzzi, B., 1996. The sources and consequences of embeddedness for the economic performance of organizations: the network effect. Am. Sociol. Rev. 61 (4), 674-698.

Van der Gaag, M.P.J., Snijders, T.A.B., 2004. Proposals for the measurement of individual social capital. In: Flap, H., Volker, B. (Eds.), Creation and Returns of Social Capital. Routledge, London, pp. 199-218.

Van der Gaag, M.P.J., Snijders, T.A.B., 2005. The resource generator: measurement of individual social capital with concrete items. Soc. Netw. 27 (1), 1-29.

Völker, B., Flap, H., 2001. Weak ties as a liability: the case of East Germany. Ration. Soc. 13 (4), 397-428.

Walker, M.E., Wasserman, S., Wellman, B., 1993. Statistical model for social support networks. Sociol. Methods Res. 22 (1), 71-98.

Wellman, B., 1979. The community question. Am. J. Sociol. 84 (5), 1201-1231.

Wolf, A.P., Huang, C.-S., 1985. Marriage and Adoption in China 1845-1945. Stanford University Press, Palo Alto, CA.

Yang, K.S., 1998. Familization, pan-familism, and organization management. In: Cheng, B.-S., Huang, K.-L., Kuo, C.-C. (Eds.), The Management in Taiwan and China. Chinese Legacies and Management in Taiwan and China, vol. 4. Yuan-Liou Publishing, Taipei, Taiwan, pp. 19-60.

Yang, M.M.-h., 1994. Gifts, Favors, and Banquets: The Art of Social Relationships in China. Cornell University Press, Ithaca, NY.

Zheng, T., Salganik, M.J., Gelman, G., 2006. How many people do you know in prison? J. Am. Stat. Assoc. 101 (474), 409-423. 